\title{
A Microwave Metamaterial Inspired Sensor for Non-Invasive Blood Glucose Monitoring
}

\author{
Jan VRBA, David VRBA \\ Dept. of Biomedical Technology, Faculty of Biomedical Engineering, Czech Technical University in Prague, \\ Zikova 4, 16636 Prague, Czech Republic \\ jan.vrba@fbmi.cvut.cz
}

\begin{abstract}
In this paper, a microwave sensor based on an artificial transmission line is proposed for non-invasive blood glucose monitoring. A corresponding numerical model of the sensor implemented in microstrip technology is created in the commercial full-wave numerical simulation tool COMSOL Multiphysics and virtually tested by means of numerical simulations. Blood-glucose solution models with various blood glucose concentrations are used as a model of a biological tissue under test. Furthermore, a possible methodology for performing non-invasive tests is proposed. Sensitivity of the sensor developed here is compared to a sensor based on a section of a conventional microstrip transmission line of the same length and width.
\end{abstract}

\section{Keywords}

Artificial transmission line, metamaterial, microwave, sensor, blood glucose, concentration, non-invasive

\section{Introduction}

As of 2015, 382 million people ( $8.3 \%$ of the world's population) have diabetes and it is expected that by 2035 , the number of people with diabetes will rise to 592 million. The costs associated with the treatment of diabetes amount to more than $11 \%$ of the global healthcare costs [1].

Knowing the blood glucose concentration (BGC) in patients with diabetes mellitus type 1 or 2 is crucial for maintaining it within physiological limits. BGC often needs to be measured several times a day. All of the presently used BGC monitoring systems are invasive, bearing a number of obvious inconveniences with them such as pain, the risk of infection, tissue damage where blood is taken, patients' fear of blood taking, and the associated costs. Due to these inconveniences, patients generally do not perform as many measurements as needed, even though regular BGC monitoring would not only significantly improve their quality of life but also decrease the cost of treatment. Furthermore, the type of device most commonly used for measuring the BGC is a handheld glucometer, which cannot be used for continuous glucose monitoring. Thus, if hyper/hypoglycemia occurs, it is often not detected.
It is evident that there is a clear demand for an inexpensive, non-invasive BGC monitoring technique.

Some of the methods currently considered for noninvasive monitoring of blood glucose include bioimpedance spectroscopy, fluorescence techniques, infrared spectroscopy, optical polarimetry, Raman spectroscopy, reverse iontophoresis and ultrasound, but none of them have found practical use yet.

There are currently four companies developing noninvasive BGC monitoring systems.

Cnoga Medical Ltd. [2] and Integrity Applications [3] launched their noninvasive BGC measurement systems in some markets in 2012 and in 2014, respectively. TensorTip CoG from Cnoga Medical uses near-infrared spectroscopy [2], while GlucoTrack from Integrity Applications [3] combines ultrasound, electromagnetic (EM) field and temperature measurements. Both of these sensors are calibrated by means of invasive measurements. The former is recommended for patients with type 2 diabetes mellitus only, and the latter passed clinical trials with only $96.5 \%$ of the measured data in A and B region of Clarke Error Grid. Another system, patented by Otis at al. [4], utilizes an electrochemical sensor integrated into the contact lens to measure glucose concentration in tears and the idea was further developed by Google Inc. [5]. And finally, MediWiSe [6] is developing a microwave (MW) system with working frequency range around $65 \mathrm{GHz}$, utilizing metamaterial (MTM) surfaces to reduce reflections on the tissue-sensor interface. MediWiSe announced they would open pre-orders for their MW device in late 2016.

MediWiSe as well as several research groups, employ for noninvasive BGC measurement the dependence of dielectric properties of blood on glucose concentration in the MW frequency range. Sensors based on MW resonators or transmission (TL) line sections detect the shift of resonance frequency and the change of electrical length, respectively, caused by the change of glucose concentration [7,8]. Some of the developed MW sensors were not validated experimentally [9]. The sensors were tested by means of numerical simulations, detecting glucose concentrations in water-glucose solutions. The sensors were based on ring, spiral and double spiral microstrip (MS) resonators. Performance of the spiral resonator was shown to be the most promising. In [10], 
MS monopole antenna was tested numerically on a layered model of biological tissues. In [11], six different MS resonators were compared numerically in terms of sensitivity, with the highest observed sensitivity being that of the spiral MS resonator.

In vitro studies have been conducted, using various types of sensors with various solutions: a sensor based on a rectangular MS patch antenna with both physiological saline-glucose as well as pig blood-glucose solutions in [12], an MS TL section with aqueous- and blood-glucose solutions in [13], waveguide with a goat blood-glucose solution in [14], a spiral MS resonator with blood phantom in [15] and with pig blood in [16].

In vivo studies tested a spiral MS resonator against a thumb [17] and on the wrist [18]. A split ring resonator was tested in [19]. All three studies have shown that it is possible to predict blood glucose concentrations in real time. In [19], encouraging agreement with the readings of an invasive glucometer was shown.

It has been reported that MW sensors based on MTM TLs can achieve significantly higher sensitivity levels than sensors based on conventional TL (more than 10 times higher) [7, 20-22]. In these studies, the interaction is very dependent on the chosen unit cell and especially on how the unit cell is implemented.

Due to the higher reported sensitivity, MTM sensors were proposed und successfully used for detecting small changes in EM properties of the material under test (MUT). Consequently, MTM sensors were proposed for detecting biomedical quantities, e.g. immobilized antibodies, single strained DNA [23] as well as DNA hybridization [21] and others. Even though the increased sensitivity of MTM sensors was demonstrated experimentally, it has been concluded that, in theory, this sensitivity can be significantly improved even further.

For the development of an EM non-invasive glucose monitoring system, knowing the dielectric properties of blood-glucose solutions is crucial. Some authors mention that the dielectric properties of some solutions reportedly mimic the dielectric properties of blood-glucose solutions, e.g. physiological saline-glucose [24] and blood plasmaglucose solutions [25, 26]. In [27, 28], it was shown that glucose influences the dielectric properties of blood significantly, but a mathematical model was not published. To the authors' best knowledge, the only papers that have published the mathematical model of dielectric properties of bloodglucose solutions are [29,30]. In [13], the authors measured the dielectric properties of blood-glucose solutions but their mathematical model was not published.

In [12], we have shown, through the results of simulations as well as measurements, that there are significant differences between the dielectric properties of physiological saline-glucose and blood-glucose solutions. Cor- respondingly, physiological saline-glucose solutions are, at least in the considered frequency range, not suitable for use as models of blood-glucose solutions for experimental design/evaluation of blood glucose level monitoring systems.

As mentioned above, artificial TL sensors have already been proposed for some biomedical applications. In this paper, to the authors' best knowledge, it is the first time these sensors are proposed for non-invasive blood glucose concentration measurement. The main goal of this paper is to show the potential and the issues of such sensors and to propose some ways to overcome these identified issues.

In Section 2, the proposed geometry, working principle and the numerical model of the sensor will be described. Numerical results will be presented in Section 3 and discussed in Section 4. Conclusions are presented in Section 5.

\section{Methods}

\subsection{Sensor Geometry and Numerical Model}

The sensor proposed here is a passive two-port sensor based on an artificial TL section implemented in the MS technology. Artificial TLs, as considered here, are inspired by conventional TLs, additionally equipped with serial capacitors and shunt inductors so that their electrical properties mimic the electrical properties of a 1D metamaterial (MTM). The sensor consists of $N_{c}$ unit cells and each unit cell is comprised of a serial interdigital capacitor and a shunt MS inductor grounded on one end using a cylindrical via hole. Each of these distributed circuit elements possesses an intrinsic shunt capacity and serial inductance, collectively forming a composite right left handed (CRLH) structure. A layout and a whole sensor are, for $N_{c}=4$, depicted in Figs. 1 and 3, respectively. A single unit cell is depicted in Fig. 2. On the top of the sensor (covering the metallic layout of the TL) a thin coating layer is proposed. The coating layer constitutes the side of the sensor that is virtually in a direct contact with the biological tissue under test. On the ground plane side, two SMA connectors are placed. The numerical ports assigned to the SMA connectors are used for the evaluation of $\mathrm{S}$-parameters. In a future prototype, the coating layer should prevent electrostatic discharge to ports of a vector network analyzer as well as reduce the loss at the sensor resulting from the dielectric and conductive loss in the biological tissue under test. In the present study, the biological tissue under test is modeled using blood-glucose solutions. Some sensor dimensions, if not dependent on other parameters or not included in the parametric study, are listed in Tab. 1. Dielectric properties of different domains in the numerical model are listed in Tab. 2. Dielectric properties of the substrate and coating layer are adopted from the GML1000 substrate from GIL Technologies. The height of the substrate, the coating layer and the blood-glucose solution is $1.5 \mathrm{~mm}, 0.1 / 0.2 \mathrm{~mm}$, $60 \mathrm{~mm}$, respectively. 


\begin{tabular}{|c|c|c|}
\hline Parameter Name & Parameter Value & Parameter Description \\
\hline$G w[\mathrm{~mm}]$ & 0.1 & Gap Between Fingers \\
$I w[\mathrm{~mm}]$ & 0.1 & Inductor width \\
$V d[\mathrm{~mm}]$ & 0.5 & Via Diameter \\
$P w[\mathrm{~mm}]$ & 1 & Via Pad Width \\
$S w[\mathrm{~mm}]$ & 1.6 & Side Pad Width \\
$L l[\mathrm{~mm}]$ & 0.2 & TL Section Length \\
$S l[\mathrm{~mm}]$ & 20 & Sensor Length \\
$N f[-]$ & $7,9,11$ & Number of Fingers \\
$N c[-]$ & $5,7,9$ & Number of unit cells \\
\hline
\end{tabular}

Tab. 1. Dimensions of the sensor.

\begin{tabular}{|c|c|c|}
\hline Domain & Relative Permittivity & $\begin{array}{c}\text { Equivalent Conductivty } \\
\varepsilon_{r}[-]\end{array}$ \\
\hline Substrate @ 2 GHz & 3.24 & 0.0014 \\
Coat. layer @ 2 GHz & 3.24 & 0.0014 \\
Blood Gluc. & Defined in [29] & Defined in [29] \\
Solution & & \\
\hline
\end{tabular}

Tab. 2. Dielectric properties of different domains of numerical model.

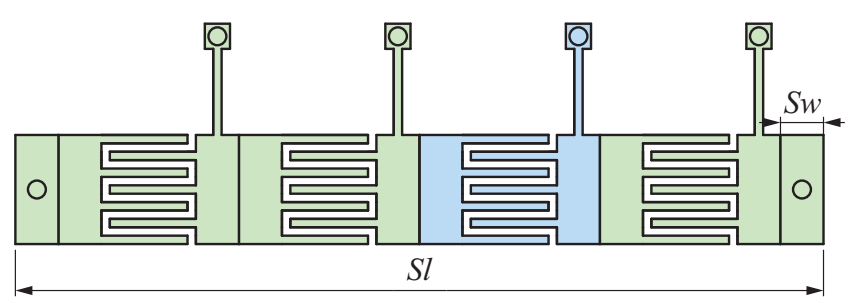

Fig. 1. Layout of the proposed artificial TL sensor with four unit cells. A single cell is marked in blue. The figure does not show proper proportions. Sensor dimensions are listed in Tab. 1 or in Sec. 3

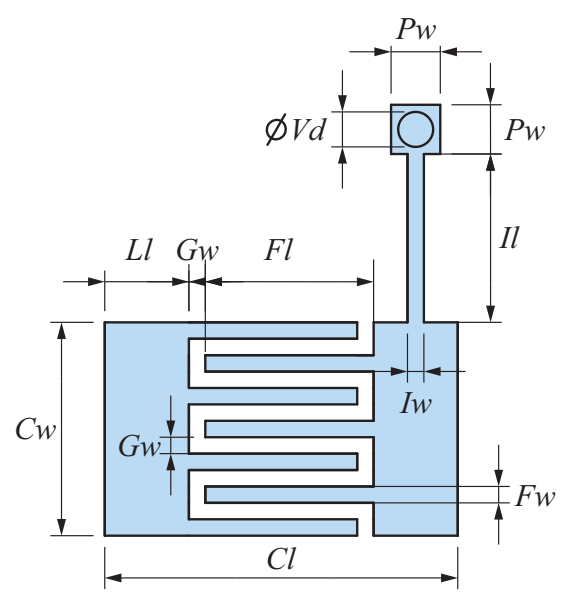

Fig. 2. Layout of the unit cell of the proposed artificial TL sensor. Figure does not show proper proportions and dimensions of the sensor are listed in Tab. 1 or in Sec. 3.

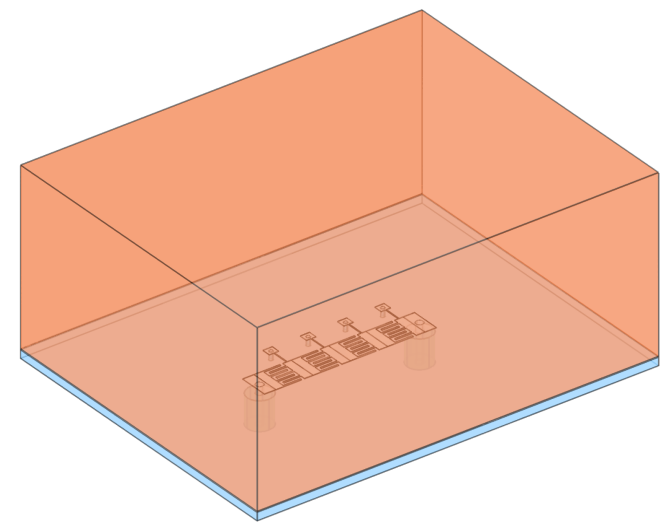

(a)

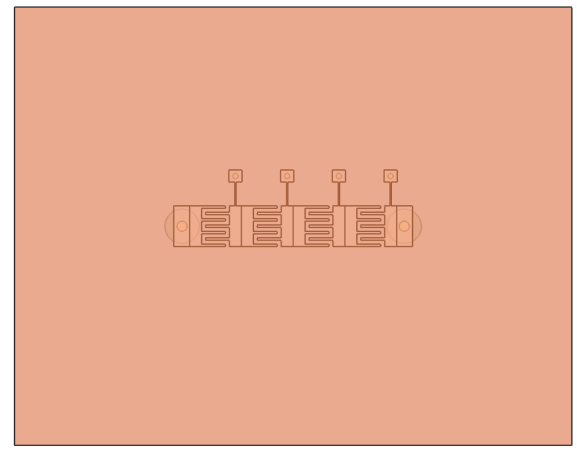

(b)

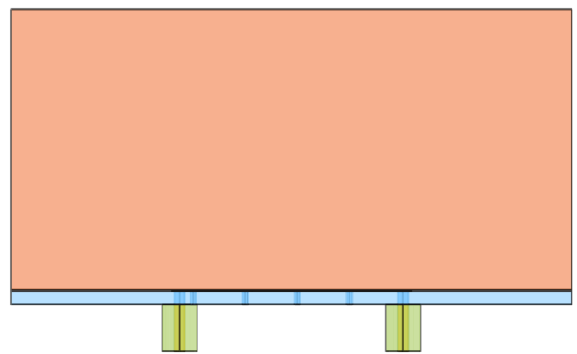

(c)

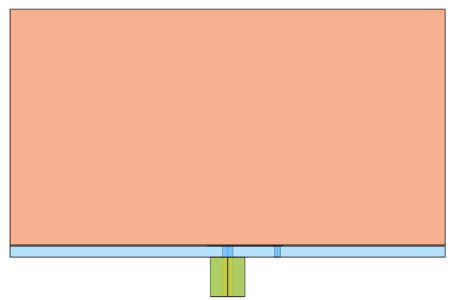

(d)

Fig. 3. Sensor and model of biological tissue (a) perspective view, $(b)$ xy view, $(c)$ zx view, $(d)$ yz view.

\subsection{Working Principle}

The phase constant $\beta$ of a TL is dependent, among others, on its effective permittivity. Since the dielectric properties of blood glucose solutions are dependent on the glucose concentration, the phase constant $\beta$ of the considered sensor is dependent on its effective dielectric properties. The phase of the transmission coefficient $S_{21}$ of the sensor is in- 
fluenced as well. The electrical quantity that is measured using a VNA is the phase shift difference of the transmission coefficient $S_{21}: \Delta \varphi=\varphi_{2}-\varphi_{1}=\ell \beta_{2}-\ell \beta_{1}=\ell \Delta \beta$ on a single working frequency $f$. While the $\beta$ of a conventional TL would be linear (for the frequency-independent effective permittivity), it is well-known (e.g. [31]) that MTM CRLH TLs show a non-linear dispersion diagram $\beta(\omega)$, as depicted for illustrative purposes in Fig. 4. For frequencies in the vicinity of the lower cut-off frequency, they show a region where, due to the negative hyperbolic dispersion diagram $\beta(\omega)$, the phase of $S_{21}$ changes rapidly. This is the region where the proposed sensor should have a higher sensitivity [21].

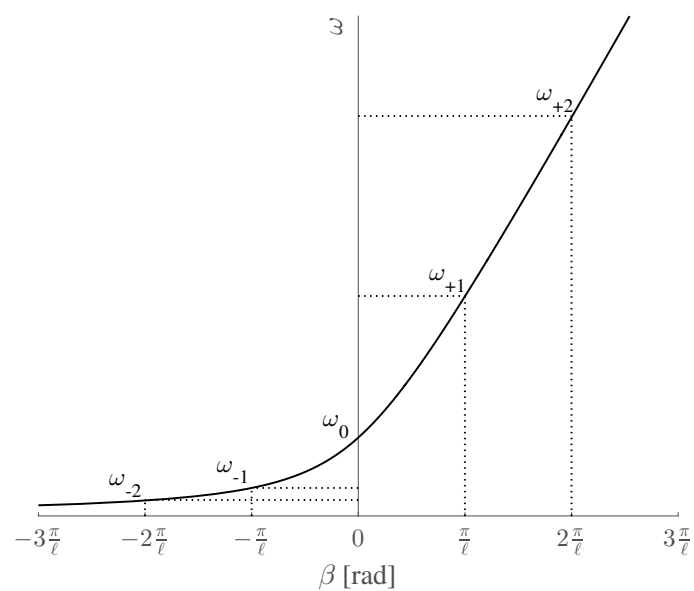

Fig. 4. Dispersion diagram of a lossless balanced CRLH TL (adapted from [31]).

\subsection{Dielectric Properties of Blood-Glucose Solution Model}

In the current work, a mathematical model of dielectric properties of blood-glucose solution was adopted from [29], implemented as a MATLAB [33] function and imported into a COMSOL Multiphysics [34] numerical model of the sensor. It has to be noted that the model from [29] is based on measurements results acquired through the use of the commercial system Dielectric Probe Kit with the Slim Probe, both by Keysight Technologies (formerly Agilent) [35]. Since it is difficult to use this equipment for liquids with inhomogeneous surface (such as blood samples would have), measurement data is affected negatively as well. Nevertheless, as mentioned earlier, there is no other mathematical model for the dielctric properties of blood-glucose solutions available in technical literature. Within the model, the real part of the complex permittivity of BG solution is dependent on frequency as well as glucose concentration, while the imaginary part is frequency-dependent only. Relative permittivity and equivalent conductivity of blood for different BGC are listed in Tab. 3. Ranges of BGC corresponding to hypoglycemia, normal glycemia, hyperglycemia are listed for readers' convenience in Tab. 4. In this paper, $\mathrm{BGC}$ in range from 0 to $250 \mathrm{mg} / \mathrm{dl}$ will be considered, covering physiological as well as non-physiological concentrations. Even though physiological BGC ranges from 72 to $108 \mathrm{mg} / \mathrm{dl}$, non-physiological concentrations as high as $250 \mathrm{mg} / \mathrm{dl}$ can be observed in diabetes patients.

\begin{tabular}{|c|c|c|}
\hline BGC [mg/dl] & Relative Permittivity & $\begin{array}{c}\text { Equivalent Conductivty } \\
\varepsilon_{r}[-]\end{array}$ \\
\hline 0 & 69.4325 & $\sigma_{e}[\mathrm{~S} / \mathrm{m}]$ \\
25 & 67.2436 & 1.4895 \\
50 & 65.0547 & 1.4895 \\
75 & 62.8658 & 1.4895 \\
100 & 60.6768 & 1.4895 \\
125 & 58.4879 & 1.4895 \\
150 & 56.2990 & 1.4895 \\
175 & 54.1101 & 1.4895 \\
200 & 51.9211 & 1.4895 \\
225 & 49.7322 & 1.4895 \\
250 & 47.5433 & 1.4895 \\
\end{tabular}

Tab. 3. Dielectric properties of blood glucose solutions at $2 \mathrm{GHz}$ for different BGC [29].

\begin{tabular}{|c|cc|}
\hline Different Conditions & \multicolumn{2}{|c|}{ BGC } \\
& {$[\mathrm{mmol} / \mathrm{l}]$} & {$[\mathrm{mg} / \mathrm{dl}]$} \\
\hline Hypoglycemia & $<4$ & $<60$ \\
Normal Glycemia & $4-6$ & $72-108$ \\
Hyperglycemia for fasting adult & $>11.1$ & $>200$ \\
Hyperglycemia 2 hours after meal & $>7$ & $>126$ \\
\hline
\end{tabular}

Tab. 4. Different conditions regarding blood glucose concentrations [32].

\section{Some Results of Parametric Study}

In the performed parametric study, the length of the sensor was set to $2 \mathrm{~cm}$ in order to ensure a compact size, reduce the number of parameters as well as to make performance comparisons of different sensors easier. Just for the purpose of comparison, the split ring resonator sensor, published in [19], has an outer diameter of the split ring of $2.9 \mathrm{~cm}$ and the overall sensor (including shielding) diameter of approximately $3.5 \mathrm{~cm}$. Furthermore, we considered two different numbers of fingers $N_{f}=7$ and 10 and width of gap between the fingers $G_{w}=0.1 \mathrm{~mm}$. The parametric study considered three different numbers of unit cells $N_{c}=4,5$, 6, 7 and 9 with different numbers of fingers of interdigital capacitors $N_{f}=7,7,7,9$ and 11 , respectively. Furthermore, different width of unit cell $C_{w}$ according to other parameters were considered. For each set of parameters, the length of inductors $I_{l}$ was adjusted to keep the lowest resonance frequency for $\mathrm{BGC}=125 \mathrm{mg} / \mathrm{ml}$ at approximately $2 \mathrm{GHz}$.

Evaluation of each sensor sensitivity starts with a simulation for $\mathrm{BGC}=125 \mathrm{mg} / \mathrm{dl}$. The working frequency of the sensor should be approx. $2 \mathrm{GHz}$ and equal to the lowest resonance frequency - a peak of simulated $\left|S_{21}\right|$. For each set of parameters the BGC was increased from 0 to $250 \mathrm{mg} / \mathrm{ml}$ in increments of $25 \mathrm{mg} / \mathrm{ml}$. The amplitude and phase of $S_{21}$ was recorded. Furthermore, the difference between the phase of $S_{21}$ for the corresponding BGC and the phase of $S_{21}$ for $\mathrm{BGC}=125 \mathrm{mg} / \mathrm{dl}$ was evaluated. Some numerical results 
and the corresponding parameter sets of the parametric study are listed in Tabs. 5-9. The phase differences for some parameter combinations and considered BGCs are plotted in Fig. 5.

\begin{tabular}{|c|c|c|c|}
\hline $\begin{array}{c}\mathrm{BGC} \\
{[\mathrm{mg} / \mathrm{dl}]}\end{array}$ & $\begin{array}{c}\left|S_{21}\right| \\
{[\mathrm{dB}]}\end{array}$ & $\begin{array}{c}\angle S_{21} \\
\left.{ }^{\circ}\right]\end{array}$ & $\begin{array}{c}\Delta \angle S_{21} \\
\left.{ }^{\circ}\right]\end{array}$ \\
\hline 0 & -12.54 & -80.67 & -10.05 \\
25 & -12.54 & -78.69 & -8.066 \\
50 & -12.56 & -76.58 & -5.96 \\
75 & -12.58 & -74.45 & -3.83 \\
100 & -12.60 & -72.93 & -2.31 \\
125 & -12.65 & -70.62 & 0.00 \\
150 & -12.67 & -68.05 & 2.57 \\
175 & -12.74 & -65.57 & 5.05 \\
200 & -12.85 & -63.00 & 7.63 \\
225 & -12.97 & -60.32 & 10.30 \\
250 & -13.12 & -57.56 & 13.06 \\
\hline
\end{tabular}

Tab. 5. Results for $N_{c}=5, N_{f}=7, f_{\text {res }}=2.020 \mathrm{GHz}$, $t_{\text {coating }}=0.2 \mathrm{~mm}, C w=1.3 \mathrm{~mm}, F l=2.86 \mathrm{~mm}, I l=$ $2.1 \mathrm{~mm}$.

\begin{tabular}{|c|c|c|c|}
\hline $\begin{array}{c}\text { BGC } \\
{[\mathrm{mg} / \mathrm{dl}]}\end{array}$ & $\begin{array}{c}\left|S_{21}\right| \\
{[\mathrm{dB}]}\end{array}$ & $\begin{array}{c}\angle S_{21} \\
\left.{ }^{\circ}\right]\end{array}$ & $\begin{array}{c}\Delta<S_{21} \\
{\left[{ }^{\circ}\right]}\end{array}$ \\
\hline 0 & -13.36 & -74.77 & -10.29 \\
25 & -13.39 & -72.85 & -8.38 \\
50 & -13.42 & -70.85 & -6.38 \\
75 & -13.46 & -68.79 & -4.31 \\
100 & -13.51 & -66.66 & -2.19 \\
125 & -13.58 & -64.47 & 0.00 \\
150 & -13.64 & -61.04 & 3.43 \\
175 & -13.74 & -58.72 & 5.76 \\
200 & -13.87 & -56.25 & 8.23 \\
225 & -14.01 & -53.78 & 10.70 \\
250 & -14.18 & -51.24 & 13.23 \\
\hline
\end{tabular}

Tab. 6. Results for $N_{c}=5, N_{f}=7, f_{\text {res }}=1.963 \mathrm{GHz}$, $t_{\text {coating }}=0.2 \mathrm{~mm}, C w=2.0 \mathrm{~mm}, F l=2.86 \mathrm{~mm}, I l=$ $1.3 \mathrm{~mm}$.

\begin{tabular}{|c|c|c|c|}
\hline $\begin{array}{c}\text { BGC } \\
{[\mathrm{mg} / \mathrm{dl}]}\end{array}$ & $\begin{array}{c}\left|S_{21}\right| \\
{[\mathrm{dB}]}\end{array}$ & $\begin{array}{c}\angle S_{21} \\
\left.{ }^{\circ}\right]\end{array}$ & $\begin{array}{c}\Delta<S_{21} \\
{\left[{ }^{\circ}\right]}\end{array}$ \\
\hline 0 & -20.39 & -114.71 & -10.91 \\
25 & -20.45 & -112.71 & -8.91 \\
50 & -20.53 & -110.64 & -6.84 \\
75 & -20.61 & -108.43 & -4.62 \\
100 & -20.66 & -106.28 & -2.48 \\
125 & -20.70 & -103.80 & 0.00 \\
150 & -20.70 & -101.13 & 2.67 \\
175 & -20.92 & -98.58 & 5.22 \\
200 & -21.08 & -95.43 & 8.38 \\
225 & -21.27 & -93.16 & 10.65 \\
250 & -21.49 & -90.26 & 13.54 \\
\hline
\end{tabular}

Tab. 7. Results for $N_{c}=7, N_{f}=9, f_{\text {res }}=1.982 \mathrm{GHz}$, $t_{\text {coating }}=0.2 \mathrm{~mm}, C w=1.7 \mathrm{~mm}, F l=1.85 \mathrm{~mm}, I l=$ $2.85 \mathrm{~mm}$.

\begin{tabular}{|c|c|c|c|}
\hline $\begin{array}{c}\text { BGC } \\
{[\mathrm{mg} / \mathrm{d}]}\end{array}$ & $\begin{array}{c}\left|S_{21}\right| \\
{[\mathrm{dB}]}\end{array}$ & $\begin{array}{c}\left\langle S_{21}\right. \\
{\left[{ }^{\circ}\right]}\end{array}$ & $\begin{array}{c}\Delta<S_{21} \\
{\left[{ }^{\circ}\right]}\end{array}$ \\
\hline 0 & -23.92 & -178.68 & -21.80 \\
25 & -24.10 & -176.79 & -19.91 \\
50 & -24.32 & -172.09 & -15.21 \\
75 & -24.41 & -167.13 & -10.25 \\
100 & -24.66 & -162.21 & -5.33 \\
125 & -24.90 & -156.88 & 0.00 \\
150 & -25.22 & -151.47 & 5.41 \\
175 & -25.54 & -145.85 & 11.03 \\
200 & -25.90 & -140.83 & 16.05 \\
225 & -26.31 & -134.71 & 22.17 \\
250 & -26.77 & -125.96 & 30.92 \\
\hline
\end{tabular}

Tab. 8. Results for $N_{c}=7, N_{f}=9, f_{\text {res }}=1.989 \mathrm{GHz}$, $t_{\text {coating }}=0.1 \mathrm{~mm}, C w=1.7 \mathrm{~mm}, F l=1.894 \mathrm{~mm}$, $I l=2.55 \mathrm{~mm}$

\begin{tabular}{|c|c|c|c|}
\hline $\begin{array}{c}\text { BGC } \\
{[\mathrm{mg} / \mathrm{dl}]}\end{array}$ & $\begin{array}{c}\left|S_{21}\right| \\
{[\mathrm{dB}]}\end{array}$ & $\begin{array}{c}\angle S_{21} \\
{\left[{ }^{\circ}\right]}\end{array}$ & $\begin{array}{c}\Delta \angle S_{21} \\
{\left[{ }^{\circ}\right]}\end{array}$ \\
\hline 0 & -25.57 & -45.21 & -34.17 \\
25 & -25.67 & -38.53 & -27.50 \\
50 & -25.76 & -31.72 & -20.68 \\
75 & -25.74 & -24.91 & -13.87 \\
100 & -25.8699 & -18.09 & -7.05 \\
125 & -26.03 & -11.04 & 0.00 \\
150 & -26.22 & -3.83 & 7.21 \\
175 & -26.46 & 3.63 & 14.67 \\
200 & -26.74 & 11.39 & 22.43 \\
225 & -27.07 & 19.50 & 30.54 \\
250 & -27.35 & 27.97 & 39.01 \\
\hline
\end{tabular}

Tab. 9. Results for $N_{c}=9, N_{f}=11, f_{\text {res }}=2.011 \mathrm{GHz}$, $t_{\text {coating }}=0.1 \mathrm{~mm}, C w=2.1 \mathrm{~mm}, F l=1.364 \mathrm{~mm}$, $I l=2.85 \mathrm{~mm}$.

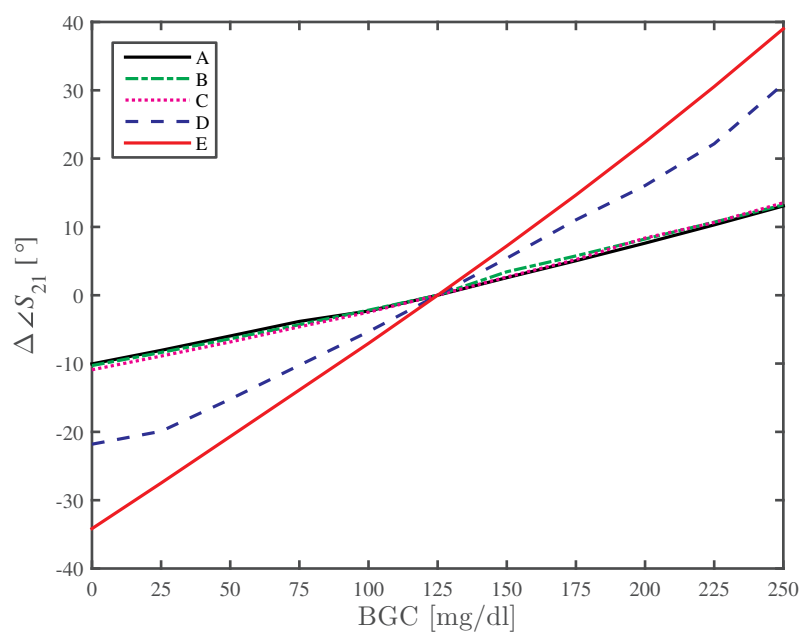

Fig. 5. Phase shift of $S_{21}$ as a function of BGC. A-E correspond to results listed in Tabs. 5-9, respectively. 


\section{Discussion}

In similar way, as each sensor sensitivity was evaluated in Sec. 3, the sensor could be used in in vivo measurements. The working frequency could be set to the value of the measured lowest resonance frequency, and the phase of $S_{21}$ at the same frequency can be used as reference for later phase measurements. Since the calibration curve (Fig. 5) of the sensor E is nearly linear, a two point patient-specific calibration could be sufficient. The two necessary BGC points could be obtained via an invasive technique.

The performance of sensors developed here was compared to performance of sensors based on sections of conventional MS TLs virtually placed in vicinity of the blood glucose solution. For the purpose of the comparison a 2D numerical model of the MS TL cross-section was set, keeping the same cross-section as of the sensor (the same substrate, strip and coating layer thicknesses; the same permittivity and conductivity of the substrate, coating layer and of the blood glucose solution; MS TL width equals to $C_{w}$ ). By means of the 2D numerical simulations, it was possible to estimate a complex propagation constant of such MS TL sensor depending on the BGC of the blood glucose solution. Considering the length of the MS TL and two extreme values of BGC, 0 and $250 \mathrm{mg} / \mathrm{dl}$, it was possible to estimate maximal phase shifts of the conventional MS TL sections. $2 \mathrm{~cm}$-long MS TLs with strip width of 1.3 and $2.1 \mathrm{~mm}$ shifts the phase of transmission coefficient at $2 \mathrm{GHz}$, about 6.03 and $4.64^{\circ}$, respectively. Artifical TL sensors with $C_{w}$ of 1.3 and 2.1 shown maximal phase shifts of 23 and $73^{\circ}$, respectively. The here developed artificial TL sensors have sensitivity of a factor from 4 to 16 times higher (for the same strip thickness) than the conventional MS TL sensors.

During the development of the sensor, it has been observed, that the thickness of the coating layer influences two important sensor properties. Without the coating layer, the amplitude of $S_{21}$ is very low and it could be a problem to accurately measure the phase of the transmission coefficient. On the other hand, too thick coating layer decreases the coupling between the biological tissue and EM waves propagating along the sensor and degrades the sensitivity. Please note the effect of coating layer thickness on sensitivity as well as on magnitude of trasmission coefficient is evident from results listed in Tabs. $7-9$.

In Tab. 5-6, properties of two different sensors which differ mainly in the thickness of the sensor $C_{w}$ are listed. It was observed that the parameter $C_{w}$ does not change sensor sensitivity significantly.

In our numerical model the parameter $L l$ was set to a fixed value. Therefore any change of number of unit cells, while the total length of the sensor $S_{l}$ was kept the same led to a decrease of a serial capacity per unit cell. Therefore we had to, for increased number of $N_{c}$, increase also the number of fingers $N_{f}$ in order to maintain resonance frequency at approximately the same value.

\section{Conclusions}

In this paper, a microwave sensor based on an artificial transmission line was proposed for non-invasive blood glucose monitoring. Corresponding numerical model was built and a parametric study was performed with the goal to find dimensions of the sensor leading to sensitivity suitable for accurate monitoring of glucose in blood. The achieved sensitivity was compared to the sensitivity of sensors based on a section of conventional MS transmission line of the same length and width. The sensitivity of the sensor proposed here is up to 16 times higher compared to the conventional MS TL sensor. Due to the relatively high number of different parameters and flexibility of the artificial transmission lines, proven already in previous works $[36,37]$, it is probable, that the sensitivity can be further increased.

\section{Acknowledgments}

This research has been supported by the Czech Scientific Foundation, project no. 14-00386P Study of Thermal and Non-Thermal Effects of High-Power EM Field on Structure of Matter and project no. 13-29857P Human Body Interactions with EM Field Radiated by Metamaterial Structures.

\section{References}

[1] International Diabetes Federation. IDF Diabetes Atlas, Sixth edition. [Online] 2013. ISBN 2930229853. Available at: www.idf.org/diabetesatlas.

[2] CNOGA Medical Ltd. [Online] Cited 2015-06-14. Available at http://www.cnoga.com/Product/Glucometer.aspx

[3] Integrity Applications. [Online] Cited 2015-06-14. Available at: http://www.integrity-app.com/wp-content/uploads/2012/10/ Integrity-Applications-Fact-Sheet-September-2014.pdf

[4] OTIS, B., LIAO, Y.-T., AMIRPARVIZ, B. Wireless Powered Contact Lens with Glucose Sensor. US Patent US20120245444A1

[5] Google Inc. [Online] Cited 2015-06-14. Available at http://googleblog.blogspot.cz/2014/01/introducing-our-smartcontact-lens.html

[6] Mediwise. [Online] Cited 2015-09-15. Available at http://www.mediwise.co.uk/.

[7] SCHUElER, M., MANDEL, C., PUENTES, M., JAKOBY, R. Metamaterial inspired microwave sensors. IEEE Microwave Magazine, 2012, vol. 16, no. 4, p. 57-68. ISSN: 1527-3342. DOI: 10.1109/MMM.2011.2181448

[8] GUARIN, G., HOFMANN, M., NEHRING, J., WEIGEL, R., FISCHER, G., KISSINGER, D. Miniature microwave biosensors: Noninvasive applications. IEEE Microwave Magazine, 2015, vol. 16, no. 4, p. 71-86. ISSN: 1527-3342. DOI: 10.1109/MMM.2015.2394024

[9] MUley, A. A., GHONGADE, R. B. Design and simulate an antenna for aqueous glucose measurement. In Proceedings of the 2014 Annual IEEE India Conference (INDICON). 2014, p. 1-6. ISBN: 978-1-4799-5362-2. DOI: 10.1109/INDICON.2014.7030620 
[10] FREER, B., VENKATARAMAN, J. Feasibility study for noninvasive blood glucose monitoring. In Proceedings of the 2010 IEEE International Symposium on Antennas and Propagation (APSURSI). 2010, p. 1-4. DOI: 10.1109/APS.2010.5561003

[11] GREEN, E. C. Design of a Microwave Sensor for Non-Invasive De termination of Blood-Glucose Concentration. Ph.D. Thesis, 2005.

[12] VRBA, J., KARCH, J., VRBA, D. Phantoms for development of microwave sensors for noninvasive blood glucose monitoring. International Journal of Antennas and Propagation, 2015, vol. 2015, Article ID 570870, p. 1-5. ISSN: 1687-5877. DOI:10.1155/2015/570870

[13] HOFMANN, M., FISCHER, G., WEIGEL, R., KISSINGER, D. Microwave based noninvasive concentration measurements for biomedical applications. IEEE Transactions on Microwave Theory and Techniques, 2013, vol. 61, p. 2195-2204. ISSN: 0018-9480. DOI: 10.1109/TMTT.2013.2250516

[14] KIM, S., KIM, J., KIM, K., LEE, J.-H., BABAJANYAN, A., FRIEDMAN, B., LEE, K. In vitro monitoring of goatblood glycemia with a microwave biosensor. Current Applied Physics, 2014, vol. 14, no. 4 p. 563-569. ISSN: 1567-1739. DOI: 10.1016/j.cap.2014.01.011

[15] YILMAZ, T., FOSTER, R., HAO Y. Towards accurate dielectric property retrieval of biological tissues for blood glucose monitoring. IEEE Transactions on Microwave Theory and Techniques, 2014, vol. 52, no. 12, p. 3193-3204. ISSN: 0018-9480. DOI: 10.1109/TMTT.2014.2365019

[16] MELIKYAN, H., DANIELYAN, E., KIM, S., KIM, J., BABAJANYAN, A., LEE, J., FRIEDMAN, B., LEE, K. Noninvasive in vitro sensing of d-glucose in pig blood. Medical Engineering, 2011, vol. 34, no. 3, p. 299-304. ISSN: 1350-4533. DOI: 10.1016/j.medengphy.2011.07.020

[17] JEAN, B., GREEN, E., MCCLUNG, M. A microwave frequency sensor for non-invasive blood-glucose measurement. In Proceedings of the IEEE Sensors Applications Symposium (SAS 2008). 2008, p. 4-7. DOI: $10.1109 /$ SAS.2008.4472932

[18] SIDLEY, M., VENKATARAMAN, J. Non-invasive estimation of blood glucose a feasibility study. In Proceedings of the 2013 IEEE Applied Electromagnetics Conference (AEMC). 2013, p. 1-2. ISBN: 978-1-4799-3266-5. DOI: 10.1109/AEMC.2013.7045069

[19] CHOI, H., NAYLON, J., LUZIO, S., BEUTLER, J., BIRCHALL, J., MARTIN, C., PORCH, A. Design and in vitro interference test of microwave noninvasive blood glucose monitoring sensor. IEEE Transactions on Microwave Theory and Techniques, 2015, vol. 63, no. 10, p. 3016-3025. ISSN: 0018-9480. DOI: 10.1109/TMTT.2015.2472019

[20] DAMM, C., SCHUESSLER, M., PUENTES, M., MAUNE, H., MAASCH, M., JAKOBY, R. Artificial transmission lines for high sensitive microwave sensors. In 2009 IEEE Sensors. 2009, p. 755-758. ISSN: 1930-0395. DOI: 10.1109/ICSENS.2009.5398538

[21] DAMM, C., BAUMGARTEN, B., PUENTES, M., MAASCH, M. JAKOBY, R. Planar sensor structure for biomedical mm-wave applications based on artificial transmission lines. In Proceedings of the 2012 37th International Conference on Infrared, Millimeter, and Terahertz Waves (IRMMW-THz). 2012. DOI: 10.1109/IRMMWTHz.2012.6380089

[22] PUENTES, M., SCHUESSLER, M., PENIRSCHKE, A., DAMM, C., JAKOBY, R. Metamaterials in microwave sensing applications. In 2010 IEEE Sensors. 2010, p. 2166-2171. ISSN: 1930-0395. DOI: 10.1109/ICSENS.2010.5690570

[23] NAGEL, M., RICHTER, F., HARING-BOL AVAR, P., KURZ, H. A functionalized THz sensor for marker-free DNA analysis. Physics in Medicine and Biology, 2003, vol. 48, p. 3625-3625. ISSN: 00319155. DOI: $10.1088 / 0031-9155 / 48 / 22 / 001$
[24] SMULDERS, P. F. M., BUYSSE, M. G., HUANG, M. D. Dielectric properties of glucose solutions in the $0.5-67 \mathrm{GHz}$ range. Microwave and Optical Technology Letters, 2013, vol. 55, p. 1916-1917. ISSN: 1098-2760. DOI: 10.1002/mop. 27672

[25] TOPSAKAL, E., KARACOLAK, T., MORELAND, E. Glucosedependent dielectric properties of blood plasma. In 2011 XXXth URSI Proceedings of the General Assembly and Scientific Symposium. 2011, p. 1-4. DOI: 10.1109/URSIGASS.2011.6051324

[26] KARACOLAK, T., MORELAND, E. C., TOPSAKAL, E. Cole-cole model for glucose dependent dielectric properties of blood plasma for continuous glucose monitoring. Microwave and Optical Technology Letters, 2013, vol. 55, p. 1160-1164. ISSN: 1098-2760. DOI 10.1002/mop. 27515

[27] HAYASHI, Y., LIVSHITS, L., CADUFF, A., FELDMAN, Y Dielectric spectroscopy study of specific glucose influence on human erythrocyte membranes. Journal of Physics D: Applied Physics. 2003, vol. 36, no. 4, p. 369-374. ISSN: 0022-3727. DOI: doi:10.1088/issn.0022-3727

[28] LIVSHITS, L., CADUFF, A., TALARY, M. S., FELDMAN, Y. Dielectric response of biconcave erythrocyte membranes to d- and 1-glucose. Journal of Physics D: Applied Physics, 2007, vol. 40, p. 15-19. ISSN: 0022-3727. DOI: 10.1088/0022-3727/40/1/S03

[29] VENKATARAMAN J., FREER, B. Feasibility of non-invasive blood glucose monitoring: In-vitro measurements and phantom models. In Proceedings of the 2011 IEEE International Symposium on Antennas and Propagation (APSURSI). 2011, p. 603-606. DOI: 10.1109/APS.2011.5996782

[30] ADHYAPAK, A.,SIDLEY, M., VENKATARAMAN J. Analytical model for real time, noninvasive estimation of blood glucose level. In Proceedings of the 2014 36th Annual International Conference of the IEEE Engineering in Medicine and Biology Society (EMBC). 2013, p. 5020-5023. DOI: 10.1109/EMBC.2014.6944752

[31] CALOZ, C., ITOH, T. Electromagnetic Metamaterials: Transmission Line Theory and Microwave Applications. New Jersey (USA): John Wiley \& Sons, 2005. ISBN: 9780471669852

[32] Diabetes.co.uk [Online] 2015. Available at: http://www.diabetes.co.uk

[33] MathWorks. Matlab 2015b, Program and User's Manual. 2015.

[34] COMSOL ab. COMSOL Multiphysics 5.1, COMSOL Multiphysics Reference Manual, 2015

[35] Keysight Technologies. Keysight Technologies 85070E, Dielectric Probe Kit, $200 \mathrm{MHz}$, to $50 \mathrm{GHz}$, technical overview. 2014.

[36] VRBA, D., VRBA, J. Novel applicators for local microwave hyperthermia based on zeroth-order mode resonator metamaterial. International Journal of Antennas and Propagation, vol. 2014, Article ID 631398, p. 1-7. ISSN: 1687-5877. DOI:10.1155/2014/631398

[37] VRBA, D., VRBA, J., RODRIGUES, D., STAUFFER, P. Numerical investigation of novel microwave applicators based on zero-order mode resonance for hyperthermia treatment of cancer. Journal of The Franklin Institute, 2015. Accepted for publication. ISSN: 0016-0032. 


\begin{abstract}
About the Authors...
Jan VRBA was born in Prague. He received his M.Sc. and Ph.D. in Electrical Engineering from RWTH Aachen University, Germany in 2006 and 2013, respectively. He is an assistant professor at the Faculty of Biomedical Engineering, Czech Technical University in Prague since 2013. His main research interests are medical and industrial MW power
\end{abstract}

applications and MW diagnostic methods in medicine.

David VRBA was born in Prague. He received his M.Sc. and Ph.D. in Electrical Engineering from CTU in Prague, in 2008 and 2012, respectively. He is currently an assistant professor at the Faculty of Biomedical Engineering, Czech Technical University in Prague. His main research interests are metamaterial structures and antennas for biomedical application. 